\title{
A Experiência Transatlântica do Padre António Vieira e o Quinto Império
}

Patrícia Vieira

Universidade de Georgetown

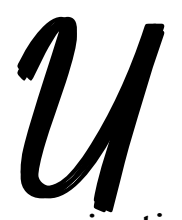

$\mathrm{m}$ dos muitos elementos que o Cristianismo herdou do Judaísmo foi a crença de que a história terminaria com a vinda do Messias, que inauguraria uma era de paz, justiça e prosperidade antes do fim do mundo. Apesar da coexistência de doutrinas cristãs e judias bastante heterogéneas, é possível identificar três elementos centrais que diferenciam a forma como as duas religiões concebem o Milénio, o termo utilizado para designar a idade messiânica, que duraria mil anos. A primeira e mais óbvia distinção reside na identidade do Messias. No Judaísmo, o Milénio coincidirá com a primeira vinda do Messias, enquanto que os Cristãos acreditam que, sendo Cristo o Redentor, Ele regressará à terra uma segunda vez para inaugurar a era messiânica. Para o povo judeu, a história é, assim, uma longa espera pela chegada do Messias, sendo que, no Cristianismo, o devir histórico nada mais é do que um interlúdio que se desenrola entre a primeira e a segunda vindas de Cristo.

Uma segunda diferença remete-nos para concepções divergentes de progresso. O Judaísmo vê a idade messiânica como uma irrupção do transcendente na história. Isto significa que não existe progresso histórico, ou seja, não há uma visão da história como um movimento que passa por diversas etapas até 
atingir a redenção no final dos tempos. ${ }^{1} \mathrm{O}$ messianismo cristão, pelo contrário, considera a história como uma longa preparação para o Milénio e identifica diferentes fases do desenvolvimento humano que correspondem a patamares na progressão em direção ao futuro Reino de Cristo.

Um outro elemento que distingue o messianismo judaico e o cristão radica no escopo da era messiânica. O povo judaico concebe a escatologia como um projeto nacional: a vinda do Messias significará o retomar da linhagem de David, a restauração de Israel à sua glória pretérita e a reconstrução do templo em Jerusalém. ${ }^{2} \mathrm{O}$ milenarismo cristão, à semelhança do próprio Cristianismo, não está associado a um só povo escolhido. Pelo contrário, a idade messiânica concebida pelos cristãos englobaria o mundo inteiro, convertido à Boa Nova.

Os escritos proféticos do Padre António Vieira (1608-1697) herdaram uma rica tradição messiânica tanto cristã como judaica, que circulava na Península Ibérica e no Brasil colonial graças a uma numerosa comunidade de judeus e cristãos-novos. Vieira postulava a vinda iminente do Reino de Cristo, que seria um "felicíssimo estado" permeado pela graça divina. Este reino seria "perfeito, completo e consumado" ${ }^{\prime 3} \mathrm{e}$ teria lugar na terra e não na esfera puramente espiritual do céu. O messianismo vieirino partilhava as principais características do milenarismo cristão acima mencionadas, nomeadamente, a crença na segunda vinda de Cristo, a ideia de progresso histórico em direção à idade milenar, e a noção de que o Reino de Cristo seria universal.

Se o conceito da segunda vinda do Redentor não sofreu uma alteração substancial durante o Renascimento, já as concepções de progresso histórico e de universalismo transformaram-se

\footnotetext{
${ }^{1}$ SCHOLEM, 1995, p. 10.

${ }^{2}$ SCHOLEM, 1995, p. 6.

${ }^{3}$ VIEIRA, 2008, p. 8.
} 
radicalmente com a expansão dos horizontes geográficos da Europa a partir do século quinze. Neste artigo, procuraremos demonstrar que a experiência transatlântica de António Vieira, que passou pela Bahia, pelo Maranhão, por Lisboa e por várias outras capitais europeias, contribuiu decisivamente para a elaboração da sua visão do Reino de Cristo na terra.

\section{A Experiência Transatlântica de Vieira}

António Vieira nasceu em Portugal em 1608 e mudou-se para a Bahia com a sua família quando era ainda criança. Durante a sua vida, o pregador viajou várias vezes entre o Brasil e Portugal. Dentro do território brasileiro, Vieira moveuse entre os centros de poder económico e político na Bahia e as remotas vilas indígenas que visitou no intuito de evangelizar a população indígena. Foi com este objetivo de "fazer grande número de cristãos da nossa doutrina"4 em mente que aprendeu tupi. Durante as suas estadias na Europa, Vieira desempenhou a função de emissário ao serviço do monarca português Dom João IV, posição que o levou a países como Espanha, França, Itália e Holanda. São particularmente relevantes para a cristalização da sua doutrina messiânica os contactos com a comunidade judaica de Amsterdão. Depois de passar cerca de seis anos na prisão acusado de heresia pela Inquisição devido ao seu milenarismo, Vieira partiu para o Vaticano, onde se tornou um pregador de renome. Regressou depois de alguns anos a Portugal, viajando em seguida para a Bahia, onde veio a falecer em 1697.

É de sublinhar nesta breve nota biográfica sobre Vieira a sua constante deslocação entre duas realidades muito distintas:

${ }^{4}$ VIEIRA, 2009, p. 344. 
por um lado, o Brasil colonial, Salvador, e, em particular, o Maranhão, onde o seu trabalho de missionário o levou aos confins da selva amazónica; por outro lado, a corte portuguesa da Restauração e os círculos intelectuais da Europa do século dezassete, incluindo Paris, Amsterdão e Roma. O messianismo vieirino é influenciado por estas experiências bastante díspares, em especial na noção de que a história progride inelutavelmente em direção ao Reino de Cristo e na concepção de uma idade messiânica de paz universal que englobaria todos os povos do mundo, unidos pela fé cristã.

\section{Progresso Histórico e o Quinto Império}

Segundo o milenarismo cristão, o devir histórico caminha para a segunda vinda de Cristo, que constituirá simultaneamente o culminar e o fim da história humana. Na versão vieirina da idade messiânica, o Reino de Cristo corresponde ao Quinto Império: “[...] depois dos três Impérios dos Assírios, Persas e Gregos, que já passaram, e depois do quarto, que ainda hoje dura, que é o Romano, há-de haver um novo e melhor Império, que há-de ser o quinto e último". ${ }^{5}$ Para Vieira, as viagens marítimas dos portugueses e a sua experiência como missionário no Brasil são prova de que o Quinto Império se aproxima. Se o advento do Reino de Cristo pressupõe a cristianização de todos os seres humanos, o trabalho missionário dos portugueses em África, na Ásia e, em especial, no Novo Mundo era o primeiro passo na conversão universal ao catolicismo.

Segundo Vieira, a expansão marítima de Portugal e os esforços missionários dos jesuítas faziam parte de um plano divino: "Porque puderam romper os Portugueses os claustros

${ }^{5}$ VIEIRA, 1982, p. 254. 
impenetráveis do Oceano e conquistaram nas outras três partes do mundo, sendo um Reino tão pequeno, tantas e tão poderosas nações, senão porque estava escrito?"'6 O pregador desenvolve este argumento na História do Futuro, ao afirmar que os profetas Isaías e Abdias previram a evangelização portuguesa do Brasil e do Maranhão, que eram na altura duas entidades administrativas separadas. ${ }^{7}$ A disseminação da doutrina cristã por todo o mundo através da pregação missionária revela assim inequivocamente que o profetizado Quinto Império, quando todos os seres humanos se tornarão cristãos, está prestes a concretizar-se.

Contudo, o contacto direto de Vieira com a realidade da colonização e da evangelização levam-no a reconhecer que a mera atividade missionária de pregadores como ele não seria suficiente para atingir o objetivo da conversão universal de todos os povos ao cristianismo. Quando considera na Representação perante o Tribunal do Santo Ofício os meios através dos quais se concretizará esta conversão, a voz da experiência fala mais alto do que as considerações do teólogo:

[...] aqueles que têm começado a penetrar as vastíssimas e ocultíssimas terras das gentilidades, e reconhecido, $[\ldots]$ as dificuldades e impedimentos [... compreendem] que a conversão das ditas gentilidades [...] se não poderá jamais conseguir pelos meios humanos e naturais [...] assi [sic] pelos lugares totalmente impenetráveis e inacessíveis em que muitas das ditas nações vivem, [...] fechados com brenhas, rios, lagos, montanhas, que de nenhum modo se podem vencer nem romper e sobretudo com a inclemência dos ares e climas [...] e diversidade incompreensível das línguas com que se distinguem $[\ldots] .^{8}$

${ }^{6}$ VIEIRA, 1982, p. 127.

7 VIEIRA, 1982, p. 210-219.

8 VIEIRA, 2008, p. 209. 
Vieira reconhece aqui pragmaticamente que, dadas as dificuldades com que se deparam os missionários, será necessário o auxílio do Espírito Santo para levar a cabo a evangelização de todos os povos profetizada no Antigo Testamento.

Nesta e em outras instâncias, Vieira baseia-se na sua familiaridade com a situação na América colonial para formular os pormenores da futura idade messiânica. Num outro texto, o pregador volta a dar primazia à experiência, em detrimento de um saber puramente teórico e especulativo: "Que podiam Crisóstomo, Agostinho e Damasceno, [...] indicar a respeito dos bárbaros brasilenses e dos restantes americanos, de quem a posteridade tardia dos mesmos Santos Padres mal havia de ter notícia passados dez séculos completos?". ${ }^{9}$ Não obstante o respeito que lhe merecem os antigos teólogos, Vieira apercebe-se de que a sua interação com a população indígena no Brasil o coloca numa posição única para compreender a vinda iminente do Reino de Cristo. Se a atividade missionária de ordens religiosas como a da Companhia de Jesus era prova do progresso histórico em direção à conversão universal dos povos aos cristianismo, o conhecimento em primeira mão de Vieira do processo de evangelização mostrou-lhe que a completa conversão das Américas não seria possível sem a intervenção da graça divina. Serão igualmente os ensinamentos da experiência e não especulações meramente teóricas que ditarão a concepção vieirina do futuro Quinto Império universal.

\section{O Reino Universal de Cristo}

A experiência transatlântica de Vieira determinou não só a sua crença no progresso histórico e na vinda iminente do Messias, anunciada pelo esforço de evangelização levado a cabo em todo o império português, mas influenciou também a

${ }^{9}$ VIEIRA, 2001, p. 106. 
sua visão do Reino de Cristo como um período que englobaria todos os povos do mundo, incluindo Judeus e Gentios, convertidos à fé cristã. ${ }^{10}$

As discussões teológicas de Vieira com membros da comunidade judaica portuguesa que viviam na Holanda, em particular com Menasseh ben Israel, que nascera na Madeira, tinha estudado em Lisboa, e vivia exilado em Amsterdão devido à perseguição dos judeus em Portugal pela Inquisição, persuadiram o pregador de que não existia qualquer incompatibilidade teológica que impedisse a coexistência de judeus e cristãos. ${ }^{11} \mathrm{E}$ mais uma vez na Representação perante o Tribunal do Santo Ofício, texto escrito em defesa das suas posições quando se encontrava preso pela Inquisição, que Vieira expõe a sua teoria sobre este assunto: "[...] digo que a esperança (material) dos Judeus se pode concordar com a fé católica [...] falo daqueles com que disputei, que são alguns Judeus de Holanda."12 Numa característica subtileza interpretativa que encontramos também com frequência na sua parenética, Vieira estabelece uma distinção entre o Messias cristão, que era filho de Deus e tinha uma natureza espiritual, e o

${ }^{10}$ Vieira identifica quatro tipos conhecidos de infidelidade: Heregia, que engloba todos os que já foram cristãos mas adoptaram depois doutrinas erróneas; Judaísmo, Gentilismo e Paganismo, categoria que inclui a população muçulmana (VIEIRA, 2008, p. 152-153). O pregador demonstra que, segundo as Escrituras, todos os tipos de infidelidade deixarão de existir na idade messiânica (VIEIRA, 2008, p. 152-170). Contudo, no caso da Heregia e do Paganismo, Vieira limita-se a provar que estes não existirão no Milénio. Quanto aos judeus e aos gentios, com os quais tivera um contacto mais próximo, Vieira descreve em pormenor o processo da sua conversão ao Cristianismo.

11 Para uma discussão pormenorizada do debate teológico entre António Vieira e Menasseh ben Israel, ver o artigo "António Vieira, Menasseh Ben Israel e o Quinto Império" de António José Saraiva.

12 VIEIRA, 2008, p. 317. 
Messias judaico, que seria um líder político e que possuía, consequentemente, uma natureza temporal. Caso os judeus aceitem o Messias espiritual dos cristãos, Vieira considera não haver nenhuma razão que os impeça de ter um líder político em Israel. ${ }^{13}$ Este rei judaico seria apenas mais um dos monarcas subordinados ao supremo imperador temporal que, junto com a autoridade espiritual do Papa, governariam o mundo durante $o$ Quinto Império de Cristo. É compreensível, argumenta Vieira, que os judeus desejem controlar politicamente a sua terra. $\mathrm{O}$ pregador assinala que os portugueses deveriam estar particularmente aptos para aprovar esta aspiração de independência, na medida em que tinham lutado recentemente contra a coroa castelhana para reconquistar a soberania sobre o seu território. ${ }^{14}$ A simpatia de Vieira pela situação judaica perpassa toda a sua obra. ${ }^{15}$ Os seus esforços para proteger os judeus portugueses e

${ }^{13}$ Eis as palavras de Vieira sobre este tema: "se tudo isto (que é a sustância da fé de Cristo) for verdadeiramente crido e recebido pelos judeus, que inconveniente nem repugnância se segue ou pode seguir de que, sobre a verdade e inteireza desta fé, conservem e lhe fique o resto material da sua esperança, isto é, que esperem haver ainda de ser restituídos à sua antiga pátria, e viver nela como gente e república separada, unida e livre, sem a sujeição, dispersão e desterro universal que hoje padecem, sujeitos, sempre e em toda a parte do mundo, a Príncipes e Senhores estranhos, e que na dita sua pátria, convertidos à fé, gozem ou hajam de gozar muito descanso, abundância e felicidades?" (VIEIRA, 2008, p. 319).

14 VIEIRA, 2008, p. 324.

15 Vieira afirma em defesa dos judeus: "Se a caída, pecado, e incredulidade dos Judeus enriqueceu todo o mundo com tantos bens espirituais e graças como foram as que todas as nações receberam por meio da pregação do Evangelho [...], quanto maiores bens e maiores graças serão as que logrará, e alcançará o mesmo mundo por meio dos ditos Judeus quando se converterem, se forem Cristãos?" (VIEIRA, 1994, p. 118). 
para facilitar o retorno a Portugal das comunidades judaicas exiladas foram certamente uma das causas da suspeição de que o pregador foi alvo, tanto em alguns círculos políticos mais ortodoxos da Restauração como por parte da Inquisição.

Noutros textos, Vieira vai ainda mais longe do que na Representação, comparando diretamente o povo português ao judaico. O pregador assinala que Deus se serviu do talento natural da populaçãojudia para o comércio de forma a propagar a doutrina do Antigo Testamento em todo o mundo: "Desta inclinação dos judeus se serviu a Providência divina para os levar [aos judeus] às terras e regiões mais remotas, [...] metendo-lhes em casa, sem uns nem outros o pretenderem, as drogas do céu entre as mercadorias da terra". ${ }^{16}$ A "verdadeira fé", que "era droga naquele tempo que só nascia na Judeia"17 chegou assim a territórios longínquos, preparando o terreno para a Boa Nova trazida, tal como no caso dos judeus, não só por pregadores mas também por comerciantes: "O primeiro rei de Portugal que se intitulou Rei do comércio da Etiópia, Arábia, Pérsia e Índia foi o que introduziu a Fé na Índia, na Pérsia, na Arábia e na Etiópia. [...] Os pregadores levam o Evangelho, e o comércio leva os pregadores" ${ }^{18}$ Vieira demonstra aqui entender pragmaticamente a dinâmica da evangelização, conhecimento que resultava da sua familiaridade com os pormenores da atividade missionária. Para além dos feudos religiosos europeus e no contexto de um objetivo mais alargado, que seria o da cristianização de todo o mundo, os judeus surgiam como aliados dos cristãos, já que, à semelhança dos portugueses, viviam espalhados pelos vários continentes, e, ao disseminar a sua religião, teriam facilitado a tarefa dos portugueses, preparando os outros povos para acatar o Novo Testamento.

16 VIEIRA, 1982, p. 321.

17 VIEIRA, 1982, p. 321.

18 VIEIRA, 1982, p. 322. 
Igualmente informada pelas suas viagens é a posição de Vieira no que diz respeito à salvação dos gentios, termo que designava todos aqueles que nunca tinham ouvido falar do Deus cristão, tais como os membros da população nativa do Brasil. Em Chave dos Profetas, obra escrita no final da sua vida, quando se encontrava de regresso à Bahia, Vieira rejeita a opinião de outros teólogos do seu tempo, segundo os quais a população nativa da América era culpada da sua ignorância em relação à fé cristã e, por esta razão, incorria num pecado mortal. O pregador afirma que os povos indígenas, na sua simplicidade, nunca poderiam ter chegado a Deus pelos seus próprios meios, sem o auxílio dos pregadores, e, deste modo, não deveriam ser considerados culpados nem punidos por não terem adoptado o Cristianismo: "Donde se conclui que os bárbaros criados nas selvas, os quais não ouviram o Evangelho ou por outra fonte não foram purificados da ignorância inata de Deus, assim como estão imunes de toda a culpa mortal, assim também estão isentos de toda a pena imortal, isto é, que há-de durar eternamente, e não são culpados por qualquer outro motivo".${ }^{19}$ A vinda da era messiânica com o Quinto Império libertaria os povos nativos do Brasil da sua ignorância e abrirlhes-ia as portas para o Reino de Cristo. Uma vez mais, Vieira enfatiza a relevância da sua experiência na América, que lhe permitiu chegar às suas conclusões: "esta matéria não se aprende estudando e discorrendo [mas] conhecendo-se pela prática e pela experiência, como que apalpada pelas mãos e observada pelos olhos [...].$^{20}$ A sua interação com a população nativa do Brasil enquanto missionário proporcionou a Vieira uma vantagem em relação aos outros teólogos, nomeadamente, o contacto direto com os "gentios", o que lhe conferia uma

\footnotetext{
${ }^{19}$ VIEIRA, 2001, p. 89.

${ }^{20}$ VIEIRA, 2001, p. 95.
} 
autoridade para discorrer sobre este assunto que os restantes autores não possuíam. ${ }^{21}$

Vieira está consciente de que o seu projeto de converter os povos indígenas do Brasil, considerando-os, assim, como potenciais membros de pleno direito do futuro Reino de Cristo, contraria as opiniões dos autores que pretendiam condenar a população nativa americana pelos seus costumes pagãos. Num exemplo de relativismo cultural avant-la-lettre, Vieira responde aos teólogos que escreviam sobre os povos indígenas da América a partir da Europa:

Aos restantes autores alegados, que são os dos nossos tempos e da nossa escola e defendem a mesma opinião [a opinião errada dos autores antigos, que ainda não tinham as vantagens do saber dos mais modernos], que direi eu? Apenas isto: que estão na Europa e escrevem na Europa.

${ }^{21}$ Em 1653 Vieira foi enviado de regresso ao Brasil para dirigir as missões dos Jesuítas no Maranhão e no Pará. É sobejamente conhecida a disputa do pregador com os colonos do Maranhão acerca da escravatura indígena: os colonos pretendiam utilizar a população nativa como mão-de-obra escrava para trabalhar nas suas terras, enquanto que Vieira pretendia mantê-la em aldeias lideradas por um padre jesuíta e por um chefe indígena. Segundo o plano de Vieira, a população indígena poderia trabalhar para os colonos mas apenas mediante o pagamento de um salário. O conflito do pregador com os colonos levou-o a escrever o famoso "Sermão de Santo António aos Peixes" (1654), no qual acusa os habitantes do Maranhão de se comportarem pior que peixes, que se comem uns aos outros. Com a morte do seu protetor, o Rei D. João IV, Vieira perde terreno no seu combate contra a avareza dos colonos maranhenses, é preso e enviado do Pará de volta a Lisboa em 1661. Num sermão que profere em Portugal no mesmo ano, Vieira pergunta-se: "Mas que será dos pobres e miseráveis índios que são a presa, e os despojos, de toda esta Guerra?" (CASTRO, 2008, p. 61). 
Lembrem-se de que grande é a diferença com que se crêem ou julgam as coisas que entram pelos ouvidos e "aquelas que são oferecidas aos olhos fiéis." Oh, quanta diferença há entre as apreciações do mais sapientíssimo, filosofando de longe sobre coisas distantes, e as de outro menos douto que, de perto, na sua presença, vê as coisas como elas são. ${ }^{22}$

Opregador continua esta passagem num tom algo irónico, no qual se entrevê um ataque velado aos sábios europeus que, ocupados em disputas retóricas, louvavam o trabalho missionário mas não se predispunham a realizar esta atividade: "Oxalá que [...] também sejam enviados os mestres, doutíssimos na Europa, que tão facilmente nos seus livros prometem que Deus deve enviar pregador ao bárbaro ignorante. Sem dúvida, é mais fácil que homens sapientíssimos, piedosos e que professam a perfeição, sejam enviados a pregar, do que conduzir à fé um bárbaro infiel" ${ }^{23}$ Vieira acusa aqui implicitamente os "mestres, doutíssimos" europeus de hipocrisia, na medida em que as palavras destes teólogos estão divorciadas de quaisquer ações concretas. A conclusão surge como o corolário da experiência transatlântica do pregador, que este considera como um abismo, separando-o dos outros autores: "É inevitável, ó mais ilustre dos teólogos, que sintais que entre os vossos raciocínios e os nossos olhos há um grande abismo e talvez maior que o próprio oceano que se estende entre nós". ${ }^{24}$

A vida de Vieira entre o Brasil e a Europa e o seu conhecimento da expansão ultramarina portuguesa, bem como da atividade missionária dos jesuítas nos vários continentes, levouo a encarar a história como o paulatino progresso da humanidade, que culminaria no Quinto Império, o Reino Milenário de Cristo na

${ }^{22}$ VIEIRA, 2001, p. 107.

23 VIEIRA, 2001, p. 107.

${ }^{24}$ VIEIRA, 2001, p. 107. 
terra. Nesta idade messiânica, a separação entre judeus, a população nativa que o pregador encontrara na América e os cristãos europeus diluir-se-ia, na medida em que todos fariam parte de um mesmo povo cristão. Vieira postula assim a universalidade baseada numa fé partilhada, noção que remete para a própria origem do catolicismo - palavra que na sua origem grega, significa precisamente "geral" ou "universal." A visão teológica de uma comunidade universal será posteriormente retomada por pensadores do Iluminismo como Jean-Jacques Rousseau ou Immanuel Kant, que secularizam este conceito e teorizam a possibilidade de paz perpétua, que uniria uma comunidade de nações com os mesmos direitos e deveres. Encontramos ainda traços da ideia de universalidade proposta por pensadores como Vieira em projetos universalistas como a noção de direito natural, de direitos humanos e, mais recentemente, de cidadania global.

Se o pensamento vieirino prefigura uma série de conceitos de universalidade que marcaram a Modernidade ocidental, tal acontece devido ao posicionamento particular do pregador, que se move entre o Velho e o Novo Mundo, antecipando no seu percurso biográfico correntes migratórias posteriores. As viagens de Vieira permitiram-lhe aperceber-se de que questões sociais, políticas e mesmo religiosas surgem radicalmente diferentes quando são contempladas a partir da América colonial, por oposição à Europa. Esta capacidade de adoptar diferentes perspectivas abre o milenarismo vieirino àqueles que eram tradicionalmente excluídos do Reino de Cristo. Ao admitir tanto judeus como a população nativa da América na sua concepção do Quinto Império, Vieira transforma a própria ideia de universalidade, entendida até então como a reprodução de uma mesma subjetividade, repetida ad infinitum. O seu legado foi o de alargar as fronteiras do Catolicismo de tal forma que o resultado final foi uma alteração profunda da própria ideia de Cristandade. O seu 
projeto teológico-político não pressupunha a dissolução de todas as diferenças políticas num só reinado, governado por um mesmo monarca, mas sim uma paz perpétua entre os reinos em que se dividem os vários povos. Na sua visão utópica do Quinto Império, especificidades culturais, linguísticas e políticas manter-se-iam, mas o conflito daria lugar à paz perpétua, mediada por uma espiritualidade cristã que funcionaria como denominador comum, permitindo a convivência em harmonia de todos os seres humanos.

\section{Obras Citadas}

CASTRO, Aníbal Pinto de. O Essencial sobre o Padre António Vieira. Lisboa: Imprensa Nacional Casa da Moeda, 2008.

SARAIVA, António José. História e Utopia: Estudos sobre Vieira. Lisboa: ICALP, 1992.

SCHOLEM, Gerschom. The Messianic Idea in Judaism and other Essays in Jewish Spirituality. Nova Iorque: Schocken Books, 1995.

VIEIRA, Padre António. Apologia das Coisas Profetizadas. Lisboa: Cotovia, 1994.

VIEIRA, Padre António. Cartas vols. I, II e III. Lisboa: Imprensa Nacional Casa da Moeda, 2009.

VIEIRA, Padre António. Chave dos Profetas. vol. III. Lisboa: Biblioteca Nacional, 2001.

VIEIRA, Padre António. História do Futuro. Ed. Maria Leonor Carvalhão Buescu. Lisboa: Imprensa Nacional Casa da Moeda, 1982.

VIEIRA, Padre António. Representação perante o Tribunal do Santo Ofício. vols. I e II. Lisboa: Imprensa Nacional Casa da Moeda, 2008. 


\section{Resumo}

Os escritos proféticos do Padre António Vieira (1608-1697) foram marcados pelas suas constantes deslocações, que lhe permitiram contactar com realidades muito distintas. Por um lado, o seu trabalho como missionário no Brasil levou-o aos confins da selva Amazónica e fê-lo aprender algumas das línguas nativas brasileiras de forma a poder comunicar com a população indígena dessas regiões. Por outro lado, o seu conhecido talento como pregador conduziu-o à corte portuguesa da Restauração, a Amsterdão, onde discutiu teologia com a membros da comunidade judaica, e aos círculos intelectuais de Roma do século dezassete. Os escritos proféticos de Vieira, onde postula o advento iminente do império de Cristo na terra - o Quinto Império - baseado na igualdade, na justiça e na paz perpetua, são inspirados nestas experiências bastante díspares. No seu império utópico, a distância entre a população nativa do Brasil que tinha encontrado na América, os Judeus, e os Cristãos da Europa diminuiria progressivamente, na medida em que todos se uniriam no Reino de Cristo por ele profetizado.

\section{Abstract}

The prophetic writings of Jesuit Priest António Vieira (1608-1697) were determined by his constant displacements between very different realities. On the one hand, his work as a missionary in Brazil led him to the confines of the Amazon jungle and prompted him to learn native Brazilian languages in order to better communicate with the indigenous population of those regions. On the other hand, his renowned skill as a preacher took him to the Portuguese court of the Restauration period, to Amsterdam, where he discussed theology with members 
of the Jewish community, and to the intellectual circles of $17^{\text {th }}$-century Rome. In his prophetic writings, where he postulates the coming of an earthly empire of Christ the Fifth Empire- predicated on equality, justice and perpetual peace, Vieira draws on these very disparate experiences. In this utopian empire, the distance between the native Brazilian population he had encountered in America, the Jews and the Christians of Europe would progressively fade, as all would come together in the kingdom of Christ he envisioned. 